\title{
THE CULTURAL FACTORS IN INTERGROUP RELATIONS IN THE MODERN WORLD (ON THE EXAMPLE OF RELIGIOUS AND ETHNIC GROUPS)

\author{
Anastasia Valiyevna Duminskaya ${ }^{1}$, Nikita Nikolayevich Yakovlev $^{2}$, \\ Denis Aleksandrovich Lesnyansky ${ }^{3}$
}

\begin{abstract}
The problem of intergroup relations becomes very important nowadays. The cultural interactions of ethnic and religious groups are influenced by the processes of globalization and migration. Considering this problem philosophically is connected with the question of how a person determines his cultural identity. There is an opinion that the world develops on the basis of contradictions. However, globalization, along with positive functions, can generate new social conflicts and aggravate old ones. Cultural conflict as a type of social interaction can perform both positive and negative functions. Relations between religious groups deserve special attention. This type of intergroup relations is often characterized with conflicts. Many local religious conflicts have political reasons. A conflict may also arise between the state and a religious group. More than that, many new religious movements (NRMs) appear, and there is an open confrontation between the traditional religious confessions and the NRMs. The ethnic aspect of intergroup relations is also very topical. In this regard, the following paradox can be noted: the weakening of the ethnic properties of culture occurs simultaneously with the strengthening of ethnic selfconsciousness. The number of ethnic groups, religions, and worldviews is rapidly increasing, and there is a transition from a homogeneous population to a pluralistic society. It can be concluded that the philosophical understanding of the processes of interaction between ethnic and religious groups is largely connected with the phenomenon of cultural self-identification. The way an individual identifies himself with this or that culture is determined by the context of intercultural interaction carried out between individuals. Depending on the situation of interindividual interaction, one or another person's knowledge about himor herself is actualized.
\end{abstract}

UDC Classification: $316,35+316,48$, DOI: $10.12955 /$ cbup.v7.1393

Keywords: Culture, society, intergroup relations, conflict, ethnicity, religion, values.

\section{Introduction}

Considering the cultural factor of intergroup relations, it should be pointed out that the word "culture" can be used in normative and descriptive meanings. In philosophical considering, culture in its normative meaning is of greater interest. In this case, the norm is identified with the "idea of culture", which is different from the very concept of "culture". The comprehension of the idea of culture is based on the idea of a person's ability to create himself in a certain sense. The philosophical understanding of culture is thus defined by "the sphere of human freedom," "the existence of man as a subject ..., as a selfdetermined being, freely setting the limits of his existence in the world" (Mezhuyev, 2012, 8).

The cultural interaction of national groups should be viewed in the context of globalization processes taking place in the modern world. Philosophical understanding of this problem is connected, first of all, with the question of how a person determines his cultural affiliation (cultural identity). In the context of a worldwide access to information, a modern person has the opportunity not only to familiarize himself with elements of almost any national culture, but also to choose the culture that he will consider "his own". This phenomenon also has a flip side, from which the awareness of one's own cultural affiliation is significantly complicated by the current situation of cultural pluralism, the availability and openness of cultural systems, as well as an impressive amount of information.

\section{Methodology}

The main method of the research is the dialectic, according to which social reality is considered, taking into account all internal connections, patterns, processes of formation and development. Such an approach made it possible to consider this type of intergroup relations as a conflict, as a stage in the development of a contradiction. Hermeneutic methods are also used in the study: understanding and interpretation. The article also uses methods of analysis and synthesis.

\section{Results and discussion}

The problem of intergroup relations and the role of factors influencing them, including cultural factors, in the context of world globalization, becomes more urgent than ever. From the philosophical point of view, the essence of globalization was clearly defined by U.S. Osipov $(2003,4,16)$, having substantiated the role of the human factor in this process: "...we are talking about a qualitatively new level of

\footnotetext{
1 Transbaikal State University, Chita, Russian Federation, talisman-rock@mail.ru

2 Transbaikal State University, Chita, Russian Federation, noderland88@mail.ru

3 Transbaikal State University, Chita, Russian Federation, superlesdenis@mail.ru
} 
unification of humanity, when different civilizations and cultures enter into direct and diverse everyday contact with each other, develop a common language, which is a complex, lengthy, fraught with conflict process".

The connection of globalization with the risk of conflict is currently being spoken by many domestic and foreign scholars who are concerned about the increasing proneness to conflict in the modern world. According to A.A. Pankin (Birzhenyuk, 2018, 146-148), the growth of conflictogenity is due to inertial factors that have historical roots, combined with modern technologies. The participants of the XVII International Likhachov Readings K.I. Kosachev, G.A. Gadzhiyev, M.V. Shmakov point to conflicts, referring to the failure of many of the postulates of liberalism and democracy, different attitudes to what the world should be governed by, and limited opportunities for self-expression in labor processes (Birzhenyuk, 2018, 146-148). At the same time, according to P.P. Tolochko (Birzhenyuk, 2018, 146148), the world "develops on the basis of contradictions, and these contradictions are very stable". The interaction of national cultures based on the principles of "universal development" will allow the avoidance of diversity caused by globalization.

Social conflicts as a type of intergroup relations play a large role in the life of all nations. Today, in the context of world globalization and the information society, a new socio-cultural space is being formed. Globalization strengthens the processes of interpenetration of cultures, religions and languages, erasing the once existing borders between states and nations. However, such a process is contradictory and, along with positive functions, can generate new social conflicts and aggravate old ones. The expansion of cultural contacts in the modern world contributes to the rapprochement of nations, but excessive active borrowing is fraught with the loss of the cultural identity of small ethnic and other groups, which can aggravate relations in society. There is the possibility of the absorption of a small culture from the larger one. Often there are radical groups of people who oppose such processes and try to protect their own identity. At some point, this can be a source of social conflict.

Cultural Conflict as a Type of Group Relationships

Cultural conflict as a phenomenon is primarily a social conflict. The famous American scientist L. Cozer $(1968,3,76)$ defined the conflict as a struggle for values and claims for a certain social status. According to another American professor L. Krisberg $(1977,17)$, social conflict is a relationship between two or more parties who are confident that they have incompatible goals. According to K. Boulding (1988, 133), conflict is a situation of rivalry in which the parties are aware of the incompatibility of possible positions, and each side seeks to occupy a position incompatible with that which the other wants to take. Based on these definitions, it is clear that social conflict is primarily a kind of collision, antagonism between individuals or social groups, arising on the basis of opposing views and goals pursued. Cultural conflict, as a rule, is based on incompatibility, rejection of ideological, evaluative, ideological, moral, ethical, religious realities. Cultural conflict is a combination of actual and possible methods and means of manifestation in the sphere of culture of categorical rejection, hostility on the individual and social levels of being. The basis of cultural conflict as an intergroup interaction are concepts such as social identity and social comparison. These concepts involve the division into friends and foes, the separation of oneself's group from the total mass of others. Through comparison and opposition, individuals identify themselves with a certain commonality, and this ensures the relative stability of intragroup relations. However, such attribution of oneself to any group, for any reason, generates a negative image of external others, even in the case when there is no clash of real interests, ideas and values.

Unsolvable contradictions between interpretations and assessments of various meanings, texts, symbols, or cultural values may lead to a state of society, which E. Durheim (1964, 368-369) refers to with the term "anomie". Anomie is a state of society when culture is no longer able to regulate people"s behavior, but people cannot rely on it and find support in it. Former values, norms, cultural patterns lose their meaning and role, and new ones did not have time to form. Anomie, being the most acute phase of the flow and exacerbation of cultural conflict at the social level, also strongly influences the individual being, causing a person to have feelings of fear, despair, frustration and insecurity in the future. The emergence of society from this state depends on the type and severity of the cultural conflict.

The list of types of cultural conflicts dictates the diversity of life itself: intergenerational conflicts (generational conflicts), subculture conflicts, class conflicts, religious conflicts. They are often based on a broader view of cultural contradiction, namely, the conflict between traditions and innovations. 
Traditions are the most stable part of the socio-cultural heritage, which is passed down from generation to generation and reproduced over a long period of time. Traditions organize organic unity with innovations, they ensure the sustainability of cultural development, and innovations provide cultural development and interaction with other cultures. The conflict in this situation will act as a way to resolve the contradiction and, with its happy outcome, will perform a positive function of selecting and assimilating the necessary cultural patterns and developing the social system as a whole. However, an uncontrolled cultural conflict that has passed into its acute phase can lead to the destruction of the existing social order.

In our opinion, in the conditions of increasing rates of globalization, informatization and technologization of society, the theory of "cultural lag" in the context of conflict interaction becomes relevant. There is an opinion that a cultural conflict performs the function of initiating the procedural dynamics of culture. Conflict in a cultural environment changes the quality of the former and creates new types of cultural forms and conflicts. Anomie and cultural lag are all qualitative forms of the realization of cultural conflict. If the anomie is a disintegration, a violation of the integrity and unity of the existing socio-cultural system, then the concepts of "cultural lag" and "cultural shock" reflect other references to cultural forms and processes. The term "cultural lag" was introduced into the system of scientific knowledge by an American sociologist, W. Ogborn $(1964,384)$. The main idea of Ogborn is that the development of material (physical) objects of culture is ahead of its spiritual development. Factors acting as causes in the material sphere of culture are: invention, accumulation, distribution, and control. In such conditions, cultural values, feelings, beliefs, ideologies, norms, ideals do not have the ability to quickly adapt to new realities and the pace of its development. Such a state itself is not bad or good; it is simply a fact of cultural lag, for the solution of which no radical measures are required. Cultural lag does not cause political stagnation, its social function is to keep the institutions and structures of society unchanged. The state and society should gradually adapt to the modern conditions of technological change in order to overcome the spiritual gap.

Thus, cultural conflict as a type of social interaction can be functional in some aspects and dysfunctional in others. It means that depending on the degree of severity, the nature of the process and the level of control, a cultural conflict can perform both positive functions and negative ones.

\section{The Cultural Characteristics of Interfaith Relations}

Relations between religious groups deserve special attention in the context of considering the cultural factor of intergroup relations. The spiritual dialogue between traditional confessions, the discovery of religious parallels, dogmatic coincidences and the identity of ethical tenets can be quite promising in order to educate the followers of religious tolerance. Deepening in dogmatic and ethical details itself does not lead to rapprochement, although it contributes to mutual understanding. For example, it is possible to find correspondences in Islamic and Christian eschatology, which makes it possible to speak of these two faiths as closely related. However, there is a significant difference in the creeds of Christianity and Islam, but both religions can exist peacefully in the same space, since Russian supernationalism aims to combine fundamentally different spiritual, cultural and ethnic worlds. M.M. Balzer, in his study Religion and Politics in Russia $(2015,25)$, indicates that in Russia, followers of any religion can freely attend churches, perform religious rites, because many nations of different religions live on its territory, and due to the developed religious tolerance, there were practically no conflicts between them.

The role of the state in such interfaith relations is also quite large, as A.J. Nieuwenhuis (2012, 153-174) writes. The principle of separation of religious associations from the state provides non-interference of the state in matters that determine the attitude of citizens to religion in the internal activities of religious associations, if this activity does not violate the requirements of the laws of the country. The state should not finance the activities of religious organizations. In turn, religious associations cannot interfere in the affairs of the state, but the ministers of these organizations have the right to participate in political activities on an equal basis with all citizens. A secular state should not support one religious organization, downplaying the importance of others. Otherwise, it can lead to sectarian clashes, such as religious wars in Africa. In Sudan, the authorities express the interests of the Muslim part of the country, which constitutes a large majority of the entire population, while the opposition is strictly focused on pagans and Christians. Moreover, the situation is complicated by the fact that the regime also fights with unorthodox Nubian Muslims, as well as with numerous Islamic sects. In Nigeria, the largest country in 
the African continent, there is an ongoing religious conflict between Christians, Muslims and pagans.

Religious Conflicts as an Example of Cultural Interaction

By religious conflict, we mean the clash of religious individuals and groups about different positions in matters of dogma, religious activity and the rules for building a religious organization. Religious conflicts are clashes between carriers of various spiritual values, representing certain religious trends (V.S. Sharma, 2018, 46-55). However, at present almost none of the current conflicts in the world is in the nature of interfaith or intrareligious confrontation in its pure form, since the political component of such wars is constantly increasing. In turn, the religious idea serves as an extremely convenient ideological feed for aggressive human masses, therefore religious and ideological clashes are most fierce, because a person is more likely to manifest his fighting qualities to protect his spiritual beliefs rather than the interests of the state, which are not always clear to himself.

There are many examples of local religious conflicts that also have political reasons. The war between Muslims and Jews over the Holy Land of Palestine, the conflict between Muslims and Hindus on the border of India and Pakistan, the clashes between Catholics-Croats and Orthodox Serbs, and also between Catholics and Protestants in Northern Ireland are just a few examples of conflicts between religious groups.

The interfaith component of an interreligious clash is caused by the initial striving of all the things in existence for the denial of uniformity. For this reason, even traditional religions have split into major sects. For example, Christianity has split into Orthodoxy, Catholicism and Protestantism. Further, Protestantism includes many sects, such as Adventism, Anglicanism, Baptism, Calvinism, Lutheranism, and others. Islam has split into Sunni, Shi' ism, Kharijism and Sufism. Buddhism has two main branches - Mahayana and Hinayana, within which there are also many schools (Tibetan Buddhism, Zen and others). Hinduism has never been a single religion. The term "Hinduism" is understood to mean the totality of the religious schools of Vishnuism, Saivism, Shaktism and Smartism. In addition, many new religious movements (NRMs) appear, the creed of which may be based on the creeds of traditional religions (Daschke, 2005). There is no doubt that there is an open confrontation between the traditional religious confessions and the NRMs, and the dialogue between them is difficult, since the uncontrolled activities of some aggressive NRMs have the character of undisguised expansion, which causes irreparable damage to human health, violates fundamental human rights, threatens the family, the society and the state.

Conflict may also arise between the state and a religious group in the framework of the struggle of aggressive atheism with religion. There are widely known examples of such conflicts in the atheist Russia of the 20th century (Froese, 2008, 38), as well as in China (Yang, 2011, 67), when the government occupied Tibet, guaranteeing widespread religious and political autonomy. This type of collision may also include confrontation between religion and the secularization processes. In the first decade of the 21 st century, a series of clashes and terrorist acts took place in Europe after the press published the cartoons insulting the religious feelings of Muslims. Criticism of the policy of multiculturalism and passive tolerance led to a series of terrorist attacks in France in November 2015. The insurmountable civilizational contradictions, behind which the cultural and religious basis is visible, entail similar conflicts.

Thus, religion plays a large role in contemporary regional conflicts, which are distinguished by an extreme threat not only to the civilian population, but also to the integrity of states. Based on this, an important task is to find ways to solve interfaith conflicts, since normal relations between religions, as well as between ethnic groups, are of great social importance. It is important that the state ensures equality between religious organizations in their rights, but the state should be neutral in matters of religious freedom, and also promote tolerance and dialogue between religions, and do everything necessary to put this into practice through various regulatory measures. Interfaith relations should be, if not friendly, then at least neutral, especially when it comes to large number of followers of religions. Servants of religious associations should promote tolerance towards other religions among believers in order to prevent religious conflicts.

\section{Ethnic Aspect of Intergroup Relations}

According to the Chinese scholar Huo Guihuan (2002, 23-27), culture should be viewed as a comprehensive phenomenon, as the main dimension that covers and permeates all levels and aspects of 
human society. The researcher points out that in modern conditions less developed countries should build their own response to the challenges of globalization and its various aspects, based on their own historical and cultural traditions, conditions of social reality, ideological and academic resources. Asking how to make such an answer effective, The Chinese author quotes Sun Tzu's famous phrase: "Know the enemy and know yourself, and you will be invincible." Huo Guihuan justifies the need to know one's own and other cultures in the process of globalization, which will contribute to the effective development of non-Western countries in modern conditions.

In this regard, when considering the ethnic aspect of intergroup relations in the modern world, the following paradox can be noted: the weakening of the ethnic properties of culture, caused by the growing influence of human universal, occurs simultaneously with the strengthening of ethnic selfconsciousness. These seemingly opposite, but objectively interrelated tendencies manifest themselves more and more expressively (Soshnikov, 2013, 9, 34).

Currently, national-cultural identity as one of the types of collective identities, develops through overcoming resistance and conflicts of traditions and innovations. It has a complex integrative character and is based on a certain set of values, which includes the concepts of freedom, national identity, patriotism, etc. In the context of globalization, collective identity becomes unstable and dynamic. Moving between different social formations and spaces, falling under the influence of a new type of information culture, many people experience an identity crisis - the inability to identify themselves with their own culture.

It should be noted that the problem of identity and globalization is not identified with the dissolution of national cultures in the global one (Rozenberg, 2014, 113). On the contrary, there is a growing need for social and ethnic communities in cultural and civilizational self-determination. This phenomenon was noted by S. Huntington (2014), pointing to the deepening of interactions between civilizations, leading to the strengthening of civilizational identity, awareness of civilizational differences. Despite the fact that under the influence of globalization in the world, the position of the national state has changed, some countries are active in the construction of national-cultural identity.

China as an Example of Creating a National Cultural Identity

The national identity of the citizens of the majority of modern states is formed under the influence of the ethnic component. One of the most striking examples of a single nation-state that unites many ethnic groups is China. In this country, the concept of a unified Chinese nation (zhonghua minzu) has an official status, implying the direction of the People's Republic of China (PRC) policy on the formation of a supra-ethnic identity. The main goal of this policy is the implementation of social communication between representatives of various beliefs and ideologies.

The formation of the national identity of the PRC is realized on the basis of the concepts of "we" and "other". The national policy of the PRC is aimed at eliminating the external "other". When confronted with the internal "other" (elements of culture of national minorities), the policy becomes aimed either at suppressing it or at incorporating it into a common national identity, since the modern state is characterized by processes of totalization of culture to cultural homogeneity (Kemayev, 2007, 22-56).

The multiethnic composition of the PRC population inevitably leads to a situation in which some ethnic groups are controlled by others. At the same time, under the influence of globalization, the process of forming a common national identity is characterized by a state of constant formation and incompleteness.

In modern China, not only national minorities, but also representatives of the predominant Han nationality do not have a single identity. Throughout the state, there is a continuous development of ethnic groups characterized by their own culture, language, and a certain self-awareness. At the same time, in its foreign policy, China focuses on the Chinese specifics associated with the country's rich history and cultural heritage.

Based on the research by K.V. Kemayev (2007, 22-56), it can be said that the integration of China's polyethnic population is possible on the basis of at least three models: a hierarchical, cross-cultural, and a "puff pie" model. In the first model, ethnic, religious and regional identities are complementary. According to the second model, members of one group define their relationship to another group differently. For example, an individual may not be aware of his national identity through membership in a particular religious group. The third proposed model combines the features of the two previous ones. 
The "puff pie" model is implemented through the integration of national minorities and the formation of a single historical memory among all ethnic groups in China.

As a multinational, multicultural state, the PRC is characterized by value conflicts between ethnic groups. The psychological trait of the Han people is a certain degree of chauvinism. In the field of culture, only elements related to their own culture are valuable to them.

While the Han culture is homogeneous, the culture of national minorities is a combination of various cultural values that enrich China's national culture. However, most of these cultural acquisitions conflict with the values of the Han people and disappear.

In the modern world, the number of ethnic groups, religions, and worldviews is rapidly increasing, and there is a transition from a homogeneous population to a pluralistic society. Therefore, the formation and development of the global world can be associated with such invariants of human activity as autonomation and integration. Throughout the existence of mankind, one can observe a cyclically-wave process in which greater cultural and civilizational complexity of historical communities led to their greater isolation within the unity, which reflected the desire to be the "insider - other" (Mosolova, 2005, 294).

\section{Conclusion}

Thus, in modern conditions, the interaction between cultural and civilizational complexes is determined by various ways of self-identification, there is a tendency for the reinterpretation of cultural identification. This trend is also typical for regional actors within the nation-states (Huntington, 1994, 33-48). At present, the regional-typical features of culture have become recognized as the most important source of human creative energy, and the diversity of human existence is considered as a factor of the self-renewal of the world.

It can be concluded that the philosophical understanding of the processes of interaction between ethnic and religious groups is largely connected with the phenomenon of cultural self-identification. It can be assumed that the way an individual identifies himself with this or that culture, with this or that sociocultural community is determined by the context of intercultural interaction carried out between individuals. A modern person realizes he belongs to the world community and feels himself to be a man of "his" culture at the same time. Awareness of oneself as a part of one or another level of socio-cultural integration depends on the situation in which the interaction takes place.

It seems that the appearance of publications on the problem of the existence of extraterrestrial civilizations in modern scientific literature (Shedrin, 2013, 30-41) is largely due to globalization processes. Pursuing the search for extraterrestrial civilizations, a man identifies himself with a single terrestrial civilization. In the interaction of representatives of different supranational regions, individuals realize their own belonging to one or another cultural and civilizational complex. Similar processes occur on other levels of regional unity. At the same time, the higher the level of this unity, the more clearly the "global identity" is shaped. Culture is connected with self-awareness. Depending on the situation of interindividual interaction, one or another person's knowledge about himself is actualized.

\section{References}

Balzer, M. M. (2015). Religion and Politics in Russia: A Reader. Routledge, 25.

Birzhenyuk, G.M. (2018). Global World: System Shifts, Challenges and Outlines of the Future. Sociological Studies, 146 148.

Boulding, K. (1988). Conflict and Defence, XIV, 133.

Coser, L. (1968). Conflict: Social Aspects. International Encyclopedia of Social Sciences, 3, 76.

Daschke, D. (2005). New Religious Movements: A Documentary Reader. New York: NY Press.

Durkheim, E. (1964). The Division of Labor in Society. Free Press edition, 368-369.

Froese, P. (2008). The Plot to Kill God: Findings from the Soviet Experiment in Secularization. Oakland: University of California Press, 38.

Huntington, S. (1994). The Clash of Civilizations? Culture and Politics. New York: Palgrave Macmillan, 99-118.

Huntington, S. (2014). The Clash of Civilizations. Retrieved from http://www.litmir.me/br/?b=11594\&p=1

Huo, G. (2002). The study of the philosophy of culture in the context of globalization. Zhexue dongtai, 4, 23-27.

Kemayev, K.V. (2007). The process of forming a pan-European identity: the policy of monetary and regulatory regulation, the mechanisms of political and economic transformation, technology, strategic modeling. Nizhny Novgorod: NSU, 22-56.

Krisberg, L. (1977). Sociology of Social Conflict. New Jersey: Prentice holl, XIV, 17. 
Mezhuyev, V.M. (2012). Philosophy of culture in the system of modern knowledge of culture. Problems of the philosophy of culture, 8 .

Mosolova, L.M. (2005). Global and regional in philosophical and cultural science of the XX century. News of the Russian State Pedagogical University, 10, 294.

Nieuwenhuis, A. J. (2012, January). State and religion, a multidimensional relationship: Some comparative law remarks. International Journal of Constitutional Law, 10 (1), 153-174.

Ogburn, W. F. (1964). On Culture and social change. Ed. by O. D. Duncan. Chicago, 384 p.

Rozenberg, N.V. (2014). National cultures as a challenge to globalization. News of higher educational institutions. Volga region, 3 (31), 113.

Shedrin, A.T. (2013). Philosophical-anthropological aspects of the problem of the search for extraterrestrial civilizations. Anthropological measurements of philosophical research, 3, 30-41.

Soshnikov, A.A. (2013). "Methodological nationalism" and "methodological cosmopolitanism": conceptualization of national realities in theoretical versions of a global society. Theory and practice of social development, 9, 34.

To the release of the "New Philosophical Encyclopedia" [Editorial]. (2003). Questions of Philosophy, 4, 16.

Vivek, S. S. (2018, Spring). What Makes a Conflict 'Religious'? The National Interest, 46-55.

Yang, F. (2011). Religion in China: Survival and Revival under Communist Rule. Oxford: Oxford University Press, 67. 